\title{
Pain characteristics of adults 65 years of age and older referred to a tertiary care pain clinic
}

\author{
Angela Mailis-Gagnon MSc MD FRCPC PhysMed ${ }^{1,2,3}$, Keith Nicholson PhD 1,3, \\ Balaji Yegneswaran MBBS ${ }^{1,3}$, Mateusz Zurowski MD MSc ${ }^{1,3}$
}

\begin{abstract}
A Mailis-Gagnon, K Nicholson, B Yegneswaran, M Zurowski. Pain characteristics of adults 65 years of age and older referred to a tertiary care pain clinic. Pain Res Manage 2008;13(5):389-394.
\end{abstract}

BACKGROUND: Reports indicate that characteristics of older adults with chronic pain may be different than those of younger persons.

OBJECTIVE: To study the pain characteristics of older patients presenting to a tertiary pain clinic for the first time.

METHODS: Age, sex and relative contributions of biomedical versus psychosocial variables contributing to chronic pain were investigated in patients 65 years of age and older, in comparison with younger patients, from a sample of 1242 consecutive new patients attending a tertiary care pain clinic. The presence of Diagnostic and Statistical Manual of Mental Disorders, Fourth Edition, Text Revision somatoform pain disorders were defined, using an explicated method of ascertaining the biomedical and psychological variables underlying the pain complaints.

RESULTS: The older patients ( $14.7 \%$ of the total sample) had relatively more physical problems (concordant with their complaints) but fewer psychological factors contributing to disability than the younger pain patients. Musculoskeletal and neuropathic disorders affected $40.7 \%$ and $35.2 \%$ of the older patients, respectively, while several patients had more than one painful disorder. Musculoskeletal problems were more prevalent in the women, and neuropathic problems were more prevalent in the men.

CONCLUSIONS: The older pain patients are a distinct group. Factors affecting the delayed presentation of older pain patients to the pain clinic and limitations of the present study are discussed.

Key Words: Chronic pain; Older adults; Pain disorder

7 he incidence, prevalence and effect of chronic pain seem to vary in different age groups. A United States National Center for Health Statistics report (1) documented the prevalence of pain in community-dwelling adults 20 years of age and older. Adults 45 to 64 years of age were the most likely to report pain lasting longer than $24 \mathrm{~h}(30 \%)$, followed by young adults 20 to 44 years of age $(25 \%)$ and adults 65 years of age and older $(21 \%)$. Adults 45 to 64 years of age were also the most likely $(17.5 \%)$ to report pain persisting for longer than three months, followed by $14.9 \%$ of adults 65 years of age and older, and $12.3 \%$ of young adults 20 to 44 years of age. These results are supported by Verhaak et al (2), who reviewed the available community and primary care studies of chronic noncancer pain and concluded that "there is greater prevalence of chronic pain in the middle aged group, who often
Caractéristiques de la douleur chez des adultes de 65 ans et plus adressés dans une clinique de la douleur d'un établissement de soins tertiaires

HISTORIQUE : Selon des rapports, les caractéristiques des adultes âgés souffrant de douleur chronique pourraient être différentes de celles des sujets jeunes.

OBJECTIF : Étudier les caractéristiques de la douleur chez des patients âgés qui se présentent dans une clinique de la douleur d'un centre de soins tertiaires pour la première fois.

MÉTHODE : Les auteurs ont analysé l'âge, le sexe, les contributions relatives des variables biomédicales versus psychosociales de la douleur chronique chez des patients de 65 ans et plus, comparativement à des patients plus jeunes provenant d'un échantillon de 1242 patients consécutifs nouvellement inscrits dans une clinique de la douleur d'un établissement de soins tertiaires. La présence de troubles douloureux somatoformes, selon la IVe édition du DSM (Diagnostic and Statistical Manual of Mental Disorders), a été établie à l'aide d'une méthode expliquée de vérification des variables biomédicales et psychologiques sous-jacentes dans les symptômes douloureux.

RÉSULTATS : Les sujets âgés (14,7\% de l'échantillon total) présentaient relativement plus de problèmes physiques concordant avec leurs symptômes, mais moins de facteurs psychologiques contribuant à leur incapacité, comparativement aux patients souffrants moins âgés. Les maladies musculosquelettiques et neuropathiques affectaient respectivement $40,7 \%$ et $35,2 \%$ des sujets âgés, tandis que plusieurs patients souffraient de plus d'un syndrome douloureux. Les problèmes musculosquelettiques étaient plus prévalents chez les femmes et les problèmes neuropathiques étaient plus prévalents chez les hommes.

CONCLUSION : Les patients âgés souffrants constituent un groupe distinct. On aborde ici les facteurs qui influent sur la consultation tardive des patients âgés souffrants dans des cliniques de la douleur et on relève les limites de la présente étude.

lack demonstrable pathology". These results are surprising, given that $70 \%$ to $85 \%$ of people 65 years of age and older experience a significant health problem that is presumed to predispose them to persistent pain (3). Somewhat contradictory results were reported in another recent large-scale community study from Norway (4), which found that persons 60 to 81 years of age were more likely to report having pain for longer than three months $(31.2 \%)$ than middle-aged (40 to 59 years of age; $27.5 \%$ ) or younger persons (18 to 39 years of age; 19.2\%). Of significance, the older group reported better adjustment. The middle-aged group had fewer discernible peripheral pathological processes to account for their pain, and the younger group had the highest rates of injuries and accidents.

Differences in presentation between older and younger adults have also been found in pain clinic studies. In a study of

${ }^{1}$ Comprehensive Pain Program; ${ }^{2}$ Krembil Neuroscience Centre, Toronto Western Hospital; ${ }^{3}$ University of Toronto Centre for the Study of Pain, Toronto, Ontario

Correspondence and reprints: Dr Angela Mailis-Gagnon, Toronto Western Hospital, 4F811, 399 Bathurst Street, Toronto, Ontario M5T 2 S8.

Telephone 416-603-5380, fax 416-603-5725, e-mail angela.mailis@uhn.on.ca 
340 patients attending a pain clinic, Corran et al (5) found that patients older than 65 years of age were less likely to have the classic chronic pain syndrome profile of high pain, high functional impact and high mood disturbance than the younger and middle-aged patients. Wijeratne et al (6) found that pain clinic patients older than 65 years of age displayed less disability and preoccupation with somatic symptoms, despite longer duration of pain and multiple medical illnesses, compared with those younger than 65 years of age. The older patients also reported lesser rate of compensation issues than the younger patients. At the commencement of the present study, the pain physician and psychiatrist intended to comment on the relative contribution of biomedical and psychological factors to presentation, in accordance with Diagnostic and Statistical Manual of Mental Disorders, Fourth Edition (DSM-IV) (7) criteria for pain disorder, to arrive at a consensus diagnosis. However, they found the endeavour difficult and it was abandoned.

A recent publication from Toronto Western Hospital (Toronto, Ontario) (8) reported that in a series of 1242 consecutive patients (16 to 93 years of age), $75 \%$ were judged to have psychological factors substantially affecting their presentation. While the issue of psychological factors in chronic pain is hotly debated, there is voluminous literature that supports the influence of such factors in pain experience and behaviour. This issue has recently been succinctly reviewed by the President of the American Academy of Pain Medicine (9).

The current report presents data on the characteristics of pain problems and the prevalence of DSM-IV, Text Revision (DSM-IV-TR) (10) pain disorders in patients 65 years of age and older who presented to the Toronto Western Hospital tertiary pain clinic for their first consultation. The data were compared to those of younger patients, and were derived from a larger observational study that examined the demographic characteristics (8) and ethnocultural factors (11) influencing the attendance of pain patients in the Toronto Western Hospital pain clinic.

\section{METHODS}

Data were collected from a consecutive series of 1242 new patients referred to the Comprehensive Pain Program (CPP) of the Toronto Western Hospital (a University of Toronto affiliated teaching hospital) at the University Health Network (Toronto, Ontario) over the course of three years (2001 to 2004), after approval by the University Health Network Research Ethics Board. All demographic data were provided by the patients through standardized intake questionnaires completed at the time of their original consultation (age, sex, place of residence, country of birth, language spoken at home, years of education, marital status, employment at onset of pain and at time of first consultation at the pain clinic, as well as body maps for patients to mark their pain areas). Clinical information was obtained at the time of the examination by experienced pain physicians, through a comprehensive history based on a standardized format and detailed neuromusculoskeletal (neuro-MSK) examination. Additionally, information was retrieved from a review of pertinent documentation (previous investigations and operative reports, if any), as well as follow-up visits and further investigations when needed. Each patient was seen initially and at follow-up by the same pain physician. All three of the physicians who participated in the present study were trained in the same pain clinic (with a collective experience of 40 years and approximately 15,000 new patients by the end of the study in 2004). Detailed recording of neuropathic pain disorders, MSK problems, and visceral and complex syndromes was obtained based on a specified list of multiple disorders created for the data collection. Examples of complex syndromes include failed back surgery syndrome and thoracic outlet syndrome - these entities are a mix of several pain types and mechanisms. If a patient had more than one medical problem, the medical problems were listed separately. Psychiatric comorbidity and determination of psychosocial factors were important parts of the clinical interview because the clinicians noted and recorded, in detail, the behaviours and psychosocial factors that may have had an impact on pain perception and/or expression. Selected patients seemed to have complex diagnoses and could not be assessed well on an outpatient basis. These patients were admitted to the inpatient unit for further investigations and lengthy behavioural observations, in addition to psychological and psychiatric assessments, in the context of a multidisciplinary team assessment.

The CPP physicians categorized diagnoses of pain disorders in accordance with the American Psychiatric Association's 1994 and 2000 versions of the DSM, the DSM-IV (7) and the DSM-IV-TR (10), respectively. This facilitated treatment decision-making, based on recognition of both medical and nonmedical factors that contribute to a patient's pain and disability. DSM-IV pain disorder diagnoses were routinely recorded in patient files over the previous 14 years. The authors' understanding developed over time with experience regarding observations obtained during encounters with patients, together with other information considered to be pertinent indicators of psychological factors contributing to presentation. For the purpose of presenting the data obtained in the current study and other similar studies $(8,11)$, the specific criteria listed below were suggested retrospectively by the pain physicians. These suggestions represent what they thought were the most salient and important criteria for arriving at a pain disorder diagnosis. The clinicians suggested that a minimum of one class A and two class B factors (see below) could be relied on to make these diagnoses. Subsequently, the proposed criteria were evaluated in a retrospective chart analysis of 30 randomly selected consultation records. Indeed, information in the charts confirmed that use of the criteria did result in the pain disorder diagnosis that had been made for the patient. In summary, two specific classes of factors relating to physical pathology (A) and psychological variables (B) have been proposed, as follows:

A) Factors related to underlying physical (organic) pathology:

1. Symptom congruence with known medical condition and/or anatomy and physiology, including pain severity and level of disability;

2. File review documenting relevant pathology (consultations, test results, operative reports, electrophysiological and other studies, etc); and

3. Abnormal specific findings on examination relevant to a given condition.

B) Factors related to psychological or behavioural variables that augment and perpetuate the pain, and are considered to be associated with the onset, maintenance, exacerbation or severity of pain: 
1. Multiple verbal and nonverbal pain behaviours (grimacing, verbalization, gestures, posturing, etc) markedly in excess of expectation given the associated pathology;

2. Significant fear of pain or pain avoidance behaviours (for example, immobilization of an arm or complete avoidance of weight-bearing in the absence of pathology warranting such a treatment);

3. Incongruent affect to pain ratings (eg, 10/10 pain ratings in a smiling and laughing patient);

4. Restricted and persistently high pain ratings (eg, pain always $8 / 10,9 / 10$ or $10 / 10$ and never lower);

5. Level of disability markedly in excess of expectation based on underlying pathology (eg, bed-bound for weeks or months after minor soft tissue injury, as in Whiplash Associated Disorder I or II; inability to perform any but the lightest of household chores or need for assistance with activities of daily living in the presence of minor, if any, pathology, etc);

6. Bizarre or nonphysiological signs incongruent with any known pathology or disease (eg, unexplainable movement disorder involving tremor, choreiform or athetoid movements, dyskinesiae, etc, bearing characteristics of psychogenic movement disorders; severe weakness or paralysis; pain generated by physiologically unrelated or simulated manoeuvres, eg, mere bending of the knee producing back pain, palpation of the shoulder generating leg pain, light compression of the head generating lower extremity or back pain, etc);

7. Inconsistent performance during interview and/or physical examination over time and situation (marked discrepancies between distraction and confrontation testing in multiple situations, such as straight leg raising, range of movement, disappearance of posturing, tremor or movement disorder under distraction or suggestion, as well as behaviour or demeanour that changes when the patient is unaware that he or she is being observed, etc);

8. Diffuse body pain elicited by light digital palpation including the trunk and/or limbs, significantly modifiable by attention or distraction, and in the absence of specific underlying joint disorder or other disorder;

9. Behaviours and pain ratings altered by the presence of a solicitous spouse or significant other, as observed by the examiner or reported explicitly to the examiners by family members;

10. Pain reported by the patient to be markedly increased by psychosocial stressors or significantly relieved by situations considered by the patient to be relaxing or not stressful;

11. Unusual patterns of pain occurrence (eg, cyclical patterns of pain appearing "always at a set time on specific days of the week" or "half an hour after getting out of bed", pain appearing suddenly after a particular exercise and remaining chronic in the absence of demonstrable pathology, pain always being the worst at night when going to bed when the patient attempts to relax and "has nothing to do" in the absence of pathology known to be associated with nocturnal pain, etc);

12. Recurrent short-term benefits or, to the contrary, recurrent pain exacerbations after multiple unrelated interventions (eg, dramatic response to a multiplicity of different medications lasting only a few days or weeks; major, multiple or bizarre side effects from all drugs used, even at miniscule doses; persistent pain generated after simple physical examination or physiotherapeutic intervention, etc);

13. Onset of pain problem occurring in the context of an emotionally charged situation which may be followed by persistent manifestations of emotional distress, eg, post-traumatic stress disorder;

14. Presence of a significant mood or anxiety disorder (other than post-traumatic stress disorder) thought to impact on pain perception and/or behaviour, conspicuously present or elicited during the interview, or documented by the treating psychiatrist or psychologist (including interventions such as antidepressants or antianxiety drugs specifically administered for a mood or anxiety disorder, electrotherapy, psychological treatments for anxiety or panic disorders, etc);

15. Known history of multiple other pain problems suggestive of psychological factors contributing to presentation or other known somatoform disorders (pseudoseizures, psychogenic movement disorders, somatization disorder, etc); or

16. Other (specify).

Based on the above system, the presence of one or more class $\mathrm{A}$ factors qualifies the patient for a chronic pain disorder diagnosis associated only with biomedical pathology (not a psychiatric diagnosis) and indicates the presence of significant and congruent physical pathology accounting for the patient's symptoms (group I). In most cases, more than one class A factor was recognized. The presence of two or more class $B$ factors alone rendered the diagnosis of a chronic pain disorder associated with psychological factors (group III). In group III, psychological factors are judged to have a major role in the onset, severity, exacerbation or maintenance of the pain. The presence of factors from both class $\mathrm{A}$ and $\mathrm{B}$ resulted in the diagnosis of a chronic pain disorder associated with both psychological factors and a general medical condition (group II).

Statistical analyses using $\mathrm{F}$ and $\chi^{2}$ statistics, as appropriate, were conducted to assess whether there were statistically significant differences among pain disorder classifications, comparing patients 65 years of age and older with patients younger than 65 years of age, and comparing adults 65 to 74 years of age and adults 75 years of age and older. Because of the small population size of adults 85 years of age and older $(n=8)$, there were no separate analyses for this subgroup. Statistical analyses were also conducted to determine whether there were age- or sex-related differences in the diagnosis of neuropathic versus MSK disorders. In addition to the $P$ value for any statistically significant finding, a measure 
TABLE 1

Summary table of data analysis $(n=182)$

\begin{tabular}{lrrrrl}
\hline Age groups & Men & Women & \multicolumn{1}{c}{$\mathbf{n}$} & $\%$ & M/F \\
\hline $65-74$ years & 38 & 62 & 100 & 55 & $1 / 1.63$ \\
$75-85$ years & 34 & 40 & 74 & 40.7 & $1 / 1.18$ \\
$>85$ years & 3 & 5 & 8 & 4.4 & $1 / 1.66$ \\
Total & 75 & 107 & 182 & & $1 / 1.43$ \\
Pain conditions & & & & & \\
\hline NeP & 32 & 32 & 64 & 35.2 & $1 / 1$ \\
MSK & 21 & 53 & 74 & 40.7 & $1 / 2.5$ \\
NeP and MSK & 15 & 10 & 25 & 13.7 & $1 / 0.67$ \\
Miscellaneous & 7 & 12 & 19 & 10 & $1 / 1.7$ \\
Pain disorder classification & & & & \\
\hline Group I & 46 & 46 & 92 & 50.5 & $1 / 1$ \\
Group II & 23 & 54 & 77 & 42.3 & $1 / 2.35$ \\
Group III & 4 & 3 & 7 & 3.9 & - \\
Other & 2 & 4 & 6 & 3.3 & - \\
\hline
\end{tabular}

Group I: Biomedical pathology; Group II: Mixed biomedical pathology and psychological factors; Group III: Psychological factors only; Miscellaneous: Group III diagnosis, not yet diagnosed and/or missing data; Other: Not yet diagnosed and/or missing data. M/F Male to female ratio; MSK Musculoskeletal; NeP Neuropathic
TABLE 2

Age group and underlying pathology congruent to complaints

\begin{tabular}{lccc}
\hline Origin of pain & $\begin{array}{c}\text { Age group } \\
\text { (years) }\end{array}$ & $\begin{array}{c}\text { Male/female } \\
\text { ratio }\end{array}$ & $\mathbf{n}$ \\
\hline NeP & $65-74$ & $1 / 1$ & 34 \\
& $75-85$ & $1 / 1$ & 27 \\
Total & $>85$ & - & 3 \\
MSK & $65-74$ & $1 / 1$ & 64 \\
& $75-85$ & $1 / 4$ & 40 \\
& $>85$ & $1 / 1.16$ & 31 \\
Total & & - & 3 \\
NeP and MSK & $65-74$ & $1 / 2.5$ & 74 \\
& $75-85$ & $1 / 0.7$ & 15 \\
& $>85$ & $1 / 0.7$ & 10 \\
Total & & - & 0 \\
Other & $65-74$ & $1 / 0.7$ & 25 \\
& $75-85$ & $1 / 1.75$ & 11 \\
& $>85$ & $1 / 1$ & 6 \\
Total & & $0 / 2$ & 2 \\
& & $1 / 1.7$ & 19
\end{tabular}

Male to female ratio was not calculated when $n<8$. 'Other' indicates mixed pathology (eg, visceral and musculoskeletal [MSK], etc), no physical diagnosis (group III), the patient had not yet been diagnosed or there were missing data. NeP Neuropathic

In terms of sex and underlying pathology, while women of effect size has been reported. References have been made to the larger sample of 1242 patients, from which this particular study group was derived, when appropriate.

\section{RESULTS}

Adults older than 65 years of age $(n=182)$ accounted for $14.7 \%$ of all new patients $(n=1242)$ seen over a three-year period in Toronto Western Hospital. There were 107 women and 75 men, ranging between 65 and 96 years of age (women) and 65 and 93 years of age (men). Within the older adult sample of 182 patients, $55 \%$ were 65 to 74 years of age, $40.7 \%$ were 75 to 85 years of age and only $4.4 \%$ were older than 85 years of age. For the entire sample of 1242 patients, statistically significant differences existed in regard to age for the three pain disorder groups $(\mathrm{F}=42.13, \mathrm{P}<0.001, \mathrm{~d}=0.5278)$. Patients presenting with only biomedical pathology were older (group I; mean [ \pm SD] age $54 \pm 16$ years) than patients with both medical and psychological factors (group II; mean age $48 \pm 14$ years) and patients with only psychological factors (group III; mean age $43 \pm 11$ years).

Statistically significant differences were observed for the pain disorder classification when directly comparing the older adults with the younger adults (Pearson $\chi^{2}=85.5, \mathrm{P}<0.001$, Cramer $\mathrm{V}=0.266)$. Unlike the overall CPP population, the older patients had a remarkably high level of discernible biomedical pathology in concordance with their complaints. Onehalf of the older patients $(50.5 \%)$ were classified as group I, as opposed to $21.1 \%$ of patients younger than 65 years of age. Furthermore, only $4 \%$ of the older patients were classified into group III, as opposed to $23.6 \%$ of the younger patients. The older patients were also less likely to present in group II $(42.3 \%)$ than those younger than 65 years of age $(52.2 \%)$. With respect to prevalence of pain disorders, there were no significant differences between patients 65 to 74 years of age, and patients 75 years of age and older. were considerably more likely to present with a pain disorder associated with psychological factors in the younger patient group (7), the latter diagnostic classification (group III) was nearly eliminated in the older adults, both in men and women. The male to female ratio was identical in the younger sample (7) of patients in group I in the large study and the older adults in the present study. There were no significant differences between the adults younger than 65 years of age and adults 65 years of age and older (both men and women) in the proportion of those who were suffering from neuropathic versus MSK disorders. Painful neuropathic disorders affected 35.2\% of the older patients, while MSK disorders affected $40.7 \%$.

However, significant differences were observed in the proportion of older men versus women presenting with neuropathic versus MSK disorders $(\mathrm{P}<0.05$, Yule $\mathrm{Q}=-0.4)$. Neuropathic and MSK disorders coexisted in $13.7 \%$ of the older adults, although neuropathic disorders were more prevalent in men (affecting $62.7 \%$ of all men) and MSK disorders were more prevalent in women (affecting 59\% of all women). MSK disorders included primarily back, shoulder, neck, hip or knee problems. Multiple MSK pathologies were seen in one-fifth $(18.7 \%)$ of the older patients, primarily in women (male to female ratio $=1 / 3.25$ ). The most common neuropathic diagnoses in this population were postherpetic neuralgia and peripheral nerve injury, each affecting $6 \%$ of the population, while the single most common MSK diagnosis was back pain, affecting $20.3 \%$ of the population. Back pain was four times more prevalent in men than women. Data are presented in detail in Tables 1 to 5 .

\section{DISCUSSION}

The present study shows that patients 65 years of age and older represented a significant minority (one of seven) of those attending Toronto Western Hospital. They differed substantially from younger patients in their diagnoses and complexities 
TABLE 3

Age group and pain disorder classification $(n=182)$

\begin{tabular}{lccc}
\hline & $\begin{array}{c}\text { Age group } \\
\text { (years) }\end{array}$ & $\begin{array}{c}\text { Male/female } \\
\text { ratio }\end{array}$ & $\mathbf{n ~ ( \% )}$ \\
\hline Group I & $65-74$ & $1 / 1$ & 46 \\
& $75-85$ & $1 / 1$ & 42 \\
Total & $>85$ & - & 4 \\
Group II & & $1 / 1$ & $92(50.5)$ \\
& $65-74$ & $1 / 3.2$ & 46 \\
Total & $75-85$ & $1 / 1.6$ & 28 \\
Group III & $>85$ & - & 3 \\
& & $1 / 2.4$ & $77(42.3)$ \\
& $65-74$ & - & 4 \\
Total & $75-85$ & - & 3 \\
Other & $>85$ & - & - \\
& & - & $7(3.9)$ \\
& $65-74$ & - & 4 \\
Total & $75-85$ & - & 1 \\
\hline
\end{tabular}

'Other' indicates that the patients are not yet diagnosed or there are missing data. Group I: Biomedical pathology; Group II: Mixed biomedical pathology and psychological factors; Group III: Psychological factors only
TABLE 4

Common neuropathic pain diagnoses $(n=182)$

\begin{tabular}{lccc}
\hline Diagnosis & $\begin{array}{c}\text { Men, \% } \\
\text { (n=75) }\end{array}$ & $\begin{array}{c}\text { Women, \% } \\
\text { (n=107) }\end{array}$ & Total, \% \\
\hline Peripheral nerve injury & 9.3 & 3.7 & 6 \\
Myelopathy & 9.3 & 0.9 & 4.4 \\
Postherpetic neuralgia & 6.7 & 5.6 & 6 \\
Painful diabetic neuropathy & 6.7 & 0.9 & 3.3 \\
Other painful neuropathy & 2.6 & 4.7 & 3.9 \\
Neuropathic pain (other) & 1.3 & 5.6 & 3.9 \\
\hline
\end{tabular}

*eg, crash injury with neuropathic characteristics, etc

TABLE 5

Common musculoskeletal (MSK) diagnoses

\begin{tabular}{lccc}
\hline Diagnosis & $\begin{array}{c}\text { \% of men } \\
(\mathbf{n}=\mathbf{7 5})\end{array}$ & $\begin{array}{c}\text { \% of women } \\
(\mathbf{n}=107)\end{array}$ & \% total \\
\hline Mechanical back pain & 9.3 & 28.0 & 20.3 \\
Joint osteoarthritis & 5.3 & 8.4 & 4.4 \\
Rotator cuff & 5.3 & 3.7 & 4.4 \\
Spinal stenosis & 5.3 & 3.7 & 4.4 \\
Other MSK pathology* & 4.0 & 4.7 & 7.1 \\
\hline
\end{tabular}

*eg, nonunion, plantar fasciitis, tennis elbow, etc

of presentation. Our data demonstrate that in our clinic, elderly patients were much more likely to present with identifiable biomedical pathology for their chronic pain; MSK factors are more prominent in women, while neuropathic conditions are more prevalent in men, in agreement with previous findings (7); and elderly patients are much less likely to have discernible psychological factors contributing to their complaints. Our finding of significant biomedical pathology in the elderly patients is in accordance with other literature reporting on elderly patients presenting with low back pain (12). While the prevalence of physical ailments increases with age, the CPP physicians do not base their diagnostic classification on the mere presence of underlying pathology (which is expected to increase with age), but on the concordance of pain complaints and related disability with detectable biomedical pathology in addition to other specific criteria.

Given the reports of under-representation of older adults in pain clinics (13), the older adults attending our pain clinic were at par or slightly over the proportion of older adults in Toronto and Ontario; Statistics Canada reports that these persons constitute $13.6 \%$ of the general population in Toronto and $12.9 \%$ in Ontario (14).

In regard to our use of the DSM-IV-TR nosology, we appreciate that there is considerable controversy surrounding the use of the pain disorder diagnosis (15). We believe that this is due to, in some part, the poor understanding or consensus about what types of psychological factors may be involved in the onset, maintenance, severity or exacerbation of pain, and which indicators of such psychological factors may be used. This poor understanding or consensus occurs despite voluminous literature indicating that such psychological factors can be important. Therefore, most primary care physicians or specialists may not feel able to provide such a diagnosis. On the other hand, those more familiar with the nature of such psychological factors (psychologists and psychiatrists) usually rely on other specialists for determination of biomedical pathology. The distinction between the biomedical and psychological basis for pain is somewhat artificial, and reflects the longstanding problem of mind-body dualism. It is nonetheless important for the clinician to appropriately weigh the biomedical and psychological contributions to the pain experience and direct management using medical treatments, psychological treatments or both, when indicated. Therefore, while we have used the DSM-IV-TR nosology for several years now, we have made concrete attempts to better define psychological factors (as described in the Methods section). The use of this nosology assists our clinical judgment regarding diagnosis and subsequent treatment. Lack of understanding of psychological contributions can lead to unnecessary or ineffective interventions, and iatrogenic complications. We must stress that we believe that psychological factors can produce or contribute to many grades of pain, including very severe pain, likely through an effect of the medial pain system interacting with the lateral pain system (16).

We and others (9) further believe that ignoring psychological factors that augment and perpetuate the pain experience may lead to undue disability, suffering and possibly iatrogenic complications, and that such factors should constitute primary management targets when appropriate. We must stress that the types and proportions of patients that we describe in our clinic population are not necessarily generalizable to general practice settings or to other pain clinics. Pain clinics differ on a multiplicity of variables (expertise, the types of patients that they attract, treatment modalities offered, waiting lists, catchment areas, etc). Furthermore, the use of the indicators of psychological factors contributing to presentation, explicated in the Methods section, may only appropriately be used by specialized pain clinicians who are familiar with the presentation of pain patients with diverse underlying conditions. A position paper further detailing our experience with this classification system and our perspective on possible revisions of the traditional 
DSM-IV classification is in preparation. We are also in the process of prospectively testing the validity and utility of the criteria explicated in the Methods section.

One must consider a multiplicity of factors that may explain why some patients present to our clinic for their first consultation after 65 years of age:

a) Despite higher levels of medical painful conditions in older age, increased pain thresholds and other ageassociated physiological changes $(17,18)$ may dull pain and delay the need for referral to a pain clinic;

b) Conditions such as shingles and the resultant postherpetic neuralgia affect mostly older adults, with prevalence increasing with age;

c) A possible referral bias may exist on behalf of family practitioners or specialists, who may seek conservative management through referral to our pain clinic for older patients with significant comorbidities after they have been deemed nonsurgical candidates;

d) Nonmedical factors, such as stoic attitude, acceptance of pain as a 'natural consequence of aging' or lower levels of entitlement may also delay seeking health care until the problem is substantial (19).

\section{REFERENCES}

1. National Center for Health Statistics, United States, 2006: With Chartbook on Trends in the Health of Americans. <http://www.cdc.gov/nchs/data/hus/hus06.pdf>. (Version current at July 17, 2008).

2. Verhaak PF, Kerssens JJ, Dekker J, Sorbi MJ, Bensing JM. Prevalence of chronic benign pain disorder among adults: A review of the literature. Pain 1998;77:231-9.

3. Ross MM, Crook J. Elderly recipients of home nursing services: Pain, disability and functional competence. J Adv Nurs 1998;27:1117-26.

4. Rustoen T, Wahl AK, Hanestad BR, Lerdal A, Paul S, Miaskowski C. Age and the experience of chronic pain: Differences in health and quality of life among younger, middle-aged, and older adults. Clin J Pain 2005;21:513-23.

5. Corran TM, Farrell MJ, Helme RD, Gibson SJ. The classification of patients with chronic pain: Age as a contributing factor. Clin J Pain 1997;13:207-14.

6. Wijeratne C, Shome S, Hickie I, Koschera A. An age-based comparison of chronic pain clinic patients. Int J Geriatr Psychiatry 2001;16:477-83.

7. Diagnostic and Statistical Manual of Mental Disorders: DSM-IV, 4th edn. Washington: American Psychiatric Association, 1994.

8. Mailis-Gagnon A, Yegneswaran B, Lakha SF, et al. Pain characteristics and demographics of patients attending a universityaffiliated pain clinic in Toronto, Ontario. Pain Res Manage 2007;12:93-9.

9. Covington EC. Psychogenic pain - what it means, why it does not exist, and how to diagnose it. Pain Med 2000;1:287-94.

10. Diagnostic and Statistical Manual of Mental Disorders: DSM-IV-TR, 4th edn, Text Revision. Washington: American Psychiatric Association, 2000. e) Older adults may have lesser predisposition to somatoform processes driving them to seek health care as converging literature evidence suggests (6); or

f) Conversely, younger patients presenting to the CPP (7) may have a greater prevalence of psychological factors, in accordance with other published literature (2). As such, patients are difficult to manage at primary care levels and ultimately end up being referred to pain clinics.

\section{CONCLUSIONS}

The present study suggests that patients older than 65 years of age who attend our pain clinic are indeed "a bird of a different colour." However, our data may not be generalizable to other clinical settings because pain clinics differ widely in philosophies, diagnostic classification, treatment approaches and types of patients. Further studies should examine the types and causes of disorders with which older adults present to primary care settings and pain clinics, their acceptance of diagnosis and proposed treatments, compliance and treatment outcomes, and ethnocultural factors, as well as attitudes and beliefs in regard to illness in general and pain in particular.

11. Mailis-Gagnon A, Yegneswaran B, Nicholson K, et al. Ethnocultural and sex characteristics of patients attending a tertiary care pain clinic in Toronto, Ontario. Pain Res Manage 2007;12:100-6.

12. Weiner DK, Sakamoto S, Perera S, Breuer P. Chronic low back pain in older adults: Prevalence, reliability, and validity of physical examination findings. J Am Geriatr Soc 2006;54:11-20.

13. Gagliese L, Melzack R. Chronic pain in elderly people. Pain 1997;70:3-14.

14. CCHS indicator profile, by sex, Canada, provinces, territories and census metropolitan areas; 2000-01. $<$ http://www.statcan.ca/english/freepub/82-576-XIE/82-576XIE2005001.htm> (Version current at July 17, 2008).

15. Sullivan MD. DSM-IV Pain Disorder: A case against the diagnosis. Int Rev Psychiatry 2000;12:91-8.

16. Vogt BA, Siker WA, Vogt LJ. Anterior cingulate cortex and the medial pain system. In: Vogt BA, Gabriel M, eds. Neurobiology of Cingulate Cortex and Limbic Thalamus: A Comprehensive Handbook. Boston: Birkhäuser, 1993:313-44.

17. Gibson SJ. Older people's pain. $<$ http://www.iasppain.org/AM/AMTemplate.cfm?Section $=$ Home $\&$ CONTENTID $=2$ 270\&TEMPLATE $=/ \mathrm{CM} /$ ContentDisplay.cfm $>($ Version current at July 17, 2008).

18. Moore AR, Clinch D. Underlying mechanisms of impaired visceral pain perception in older people. J Am Geriatr Soc 2004;52:132-6.

19. Yong HH. Can attitudes of stoicism and cautiousness explain observed age-related variation in levels of self-rated pain, mood disturbance and functional interference in chronic pain patients? Eur J Pain 2006;10:399-407. 


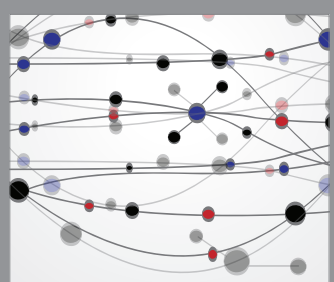

The Scientific World Journal
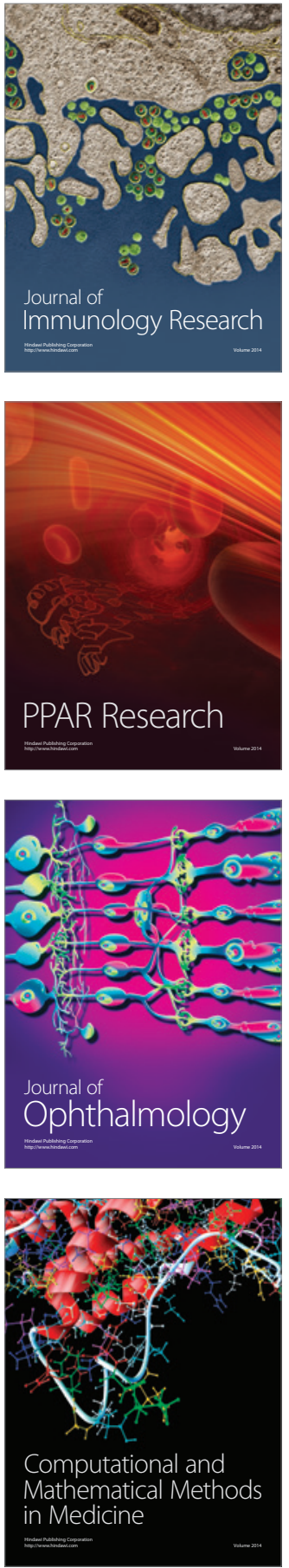

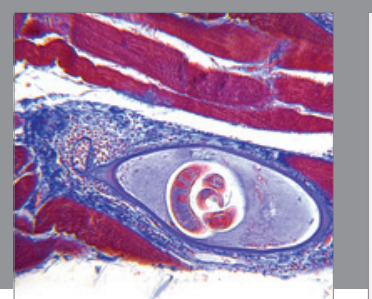

Gastroenterology Research and Practice

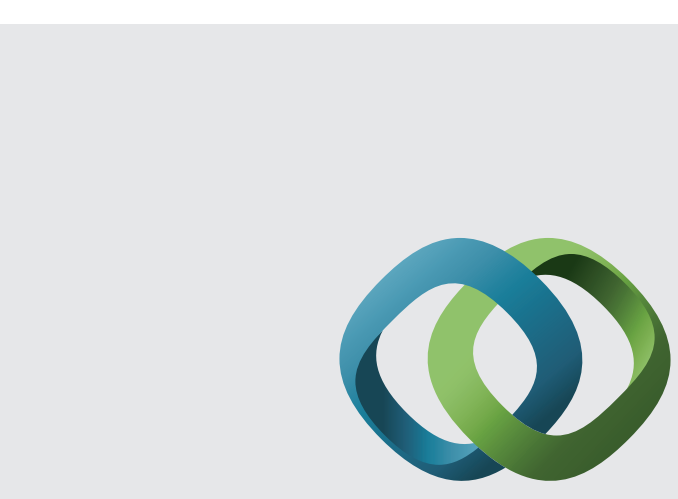

\section{Hindawi}

Submit your manuscripts at

http://www.hindawi.com
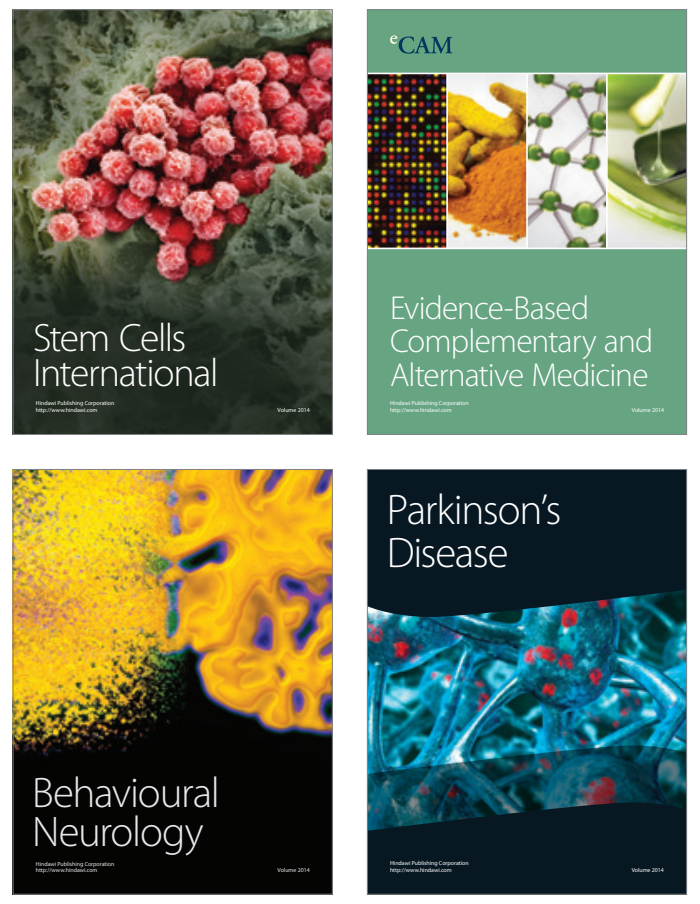
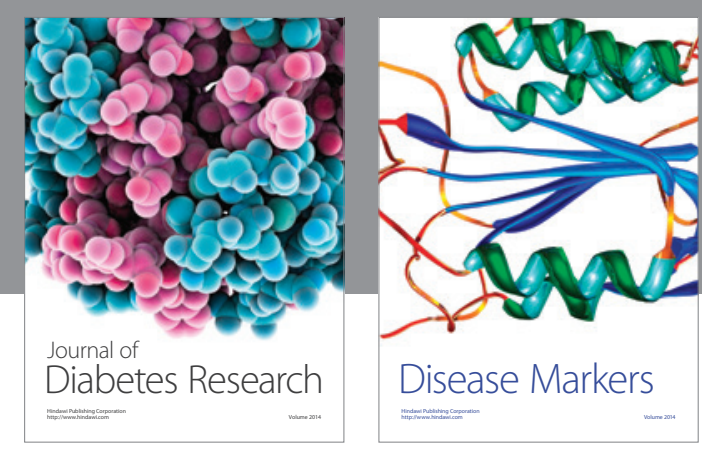

Disease Markers
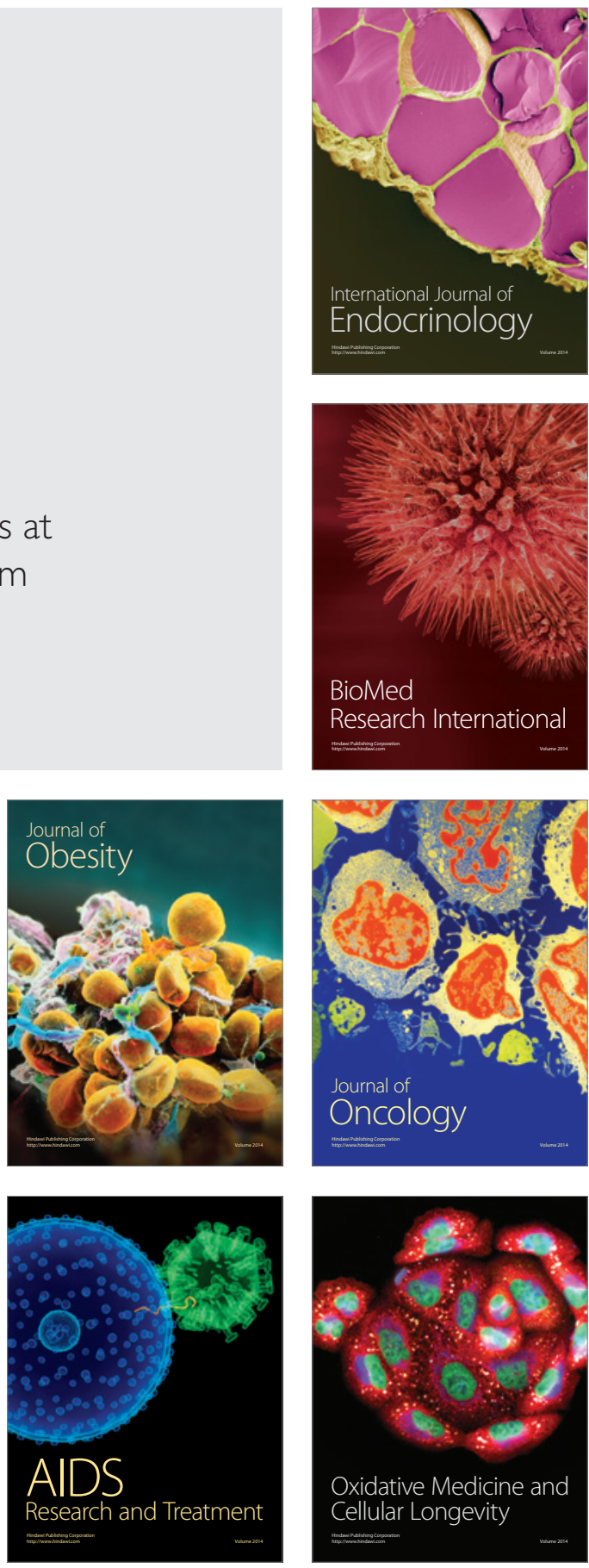